\title{
Climate change and disaster management: reducing risk, saving lives
}

\author{
K. Duncan \\ Health Studies, University of Toronto at Scarborough, Canada
}

\begin{abstract}
Recently, there has been a disturbing increase in the number of natural disasters: for example, in 1998, Hurricane Mitch caused 7,500 deaths in El Salvador, Guatemala, Honduras, and Nicaragua, and flooding in China affected 180 million people, destroyed nearly seven million homes, and killed close to 4,000 people. In 1999, a cyclone in India affected 10-15 million people and killed 10,000; and in 2000, floods in Mozambique left 330,000 homeless, and killed 500 people.

Natural disasters of medium size and stronger caused at least 25,000 deaths around the world in 2001, more than double the number of the previous year, and economic losses of US \$36 billion. More recently, human-made and natural disasters in 2004 claimed more than 21,000 lives worldwide and economic losses of US \$105 billion. The year 2005 further tested the international relief community with 'unparalleled frequency and scale of natural disaster'; Hurricane Katrina alone destroyed 300,000 homes, displaced 770,000 people, and cost US $\$ 200$ billion.

In the future, climate change is likely to mean higher maximum temperatures and more intense precipitation (with concomitant increased avalanches, floods, mudslides, etc.). Because disaster response professionals and emergency managers from all levels of government, the military, the private sector, and volunteer organizations are often the first people 'on the ground' during/following an extreme weather event, this paper will explore what climate change may mean for disaster managers, how climate change may affect the environments in which they work, and how best to reduce risks, and save lives.
\end{abstract}

Keywords: climate change, heat waves, extreme weather events, disaster management. 


\section{Introduction}

According to the Intergovernmental Panel on Climate Change (IPCC)'s Fourth Assessment Report, 'warming of the climate is now unequivocal, as is now evident from observations of increases in global air temperatures, widespread melting of snow and ice, and rising global average sea level.' More disturbing is the fact that most of the observed warming is likely due to increased concentrations of greenhouse gases (GHGs).

Continued GHG emissions at or above current rates would cause further warming 'and induce changes in the global climate system that would very likely be larger than those observed during the 20th century'. Global mean temperature is projected to increase $1.1-6.4^{\circ} \mathrm{C}$ over the coming century (IPCC [1]), a rise greater than any increase experienced by humans during the past 10,000 years (Houghton et al., [2,3]; and Cohen and Miller [4]). At the poles, warming will be much greater than for the Earth as a whole, with northern Canada's mean winter temperature increasing by $8-10^{\circ} \mathrm{C}$ (Cohen and Miller [4]).

Warming will profoundly affect the Earth; glaciers and permafrost will melt, and sea levels will rise 0.09 to $0.88 \mathrm{~m}$ (Houghton et al., [3]). Currently, 46 million people experience flooding due to storm surges (an abnormal rise in sea level along a shore primarily due to the winds of a storm); a half metre sea-level rise would increase the number of vulnerable to 92 million, and a one metre sealevel rise would increase the number of vulnerable to 118 million (Duncan [5]).

It is important to recognize that susceptibility to climate change differs across countries, populations, regions and sectors (Cohen and Miller [4] and McCarthy et al., [6]). Small oceanic islands and deltas are particularly susceptible to a onemetre rise in sea level. In the absence of mitigation, such as building sea walls, land losses might be $1.0 \%$ for Egypt, $6.0 \%$ for the Netherlands, $17.5 \%$ for Bangladesh, and $80 \%$ for the Marshall Islands. Millions of people would lose their homes, and some low-lying small-island states might disappear (McCarthy et al. [6]; World Summit on Sustainable Development [7]; and Duncan [5]).

\section{Predicted impacts}

\subsection{Thermal extremes}

In a warmer world, heat waves are expected to become more frequent and severe. An increased frequency and severity of heat waves may lead to an increase in illness (e.g. fainting, heat cramps, heat exhaustion, and heat rash) and death, particularly among the young, the pregnant, the elderly, the poor, those with cardiac or respiratory problems, those who do not thermoregulate, and those who live in the top floors of apartment buildings and lack air conditioners, especially in large urban areas (Duncan et al., [8]; and Cohen and Miller [4]).

For example, in 1995, 726 people in Chicago died from the heat; the dead were housed in ice trucks in the streets, as there was no room to house the hundreds of bodies in the city morgue (Duncan et al., [8]). More recently in 2003, over 35, 000 people succumbed-18,500 in France, 7,000 in Germany, 
8,000 in Spain and Italy, and 2,000 in the United Kingdom-in Europe because of the heat (WHO [9]).

Significant qualitative and quantitative data suggest that men and women differ in their response to extreme thermal environments. Women sweat less, have a higher working metabolic rate, and have thicker subcutaneous fat that prevents them from cooling themselves as efficiently as men. Women, as a population, are therefore less tolerant of an imposed heat stress; acclimatization, body size, and cardiovascular fitness are important factors in determining tolerance.

In 1984 , mean daily temperatures rose from $21.1^{\circ} \mathrm{C}$ in the preceding week to $28.9^{\circ} \mathrm{C}$ during a heat wave in New York. Throughout the extreme weather, noninstitutionalized elderly, particularly women, were at highest risk of heatassociated death: among those aged 75-84 years, death rates rose 39\% for men, and $66 \%$ for women; among those over 85 years old, increases were $13 \%$ for men and 55\% for women (MMWR [10]; and Duncan [11,12]).

Increased risk of heat-related illness may have to be part of future planning for community-wide events in the future, as climate change is already having an impact on sporting events. The Boston Globe reported on April 20, 2004, that: 'More than 1,100 runners suffered dehydration, heart ailments, and other medical problems at the Boston Marathon ... in near-record heat, more than twice as many injuries as medical officials have seen in recent years. The temperature reached 85 degrees, the hottest marathon since 1987, when the high was $87^{\prime}$ (Duncan [13]).

More recently, officials of the 2007 Chicago Marathon decided to turn off the clocks before many runners completed the course. The question in hindsight: was it prudent to start the race in the first place, as 40,000 athletes were potentially put at risk?

Fortunately, heat-related illness and death are largely preventable through the use of air conditioners, increased intake of fluids, the development of community-wide heat emergency plans, and improved heat-warning systems (Duncan et al., [8]; Cohen and Miller [4]; and Duncan [12]).

\subsubsection{Changing environment}

The environment of disaster management is changing, as temperature is already shifting: the Earth's ten warmest years (of the last 150 years) have all occurred since 1994, and the year 2007 is predicted to be the warmest or second warmest yet.

Therefore, what do rising temperatures mean for community-wide events? Will disaster managers have a larger role in community event planning? Will event dates have to be changed to accommodate changing temperatures? Marathons, for example, typically take place in the spring and fall to avoid very hot temperatures; will these races have to be delayed to avoid harmful temperatures, and increased risks of health effects?

What are the responsibilities of disaster managers during a heat event? Are the responsibilities identifying vulnerable people and vulnerable parts of the city, or do they include physically going in to these areas, and taking people to cooling centers? 
Will disaster managers have to have an increased presence at events or at hospitals to meet possible increasing demand (Duncan [13])? For example, the German heat warning system is controlled at the country level, but health officials at the regional level decide if they warn the population or not, and implement interventions, including increasing hospital staff (Kovats and Kristie [14]).

\subsection{Extreme weather events}

Extreme weather events include hurricanes, thunderstorms, tornadoes, etc.; recently, there has been a disturbing increase in the number of natural disasters. In 1998, Hurricane Mitch caused 7500 deaths in El Salvador, Guatemala, Honduras, and Nicaragua, and flooding affected 180 million people, destroyed nearly seven million homes, and killed 4,000 people in China. In 1999, a cyclone in India affected 10-15 million people and killed 10,000; and in 2000, floods in Mozambique left 330,000 homeless, and killed 500 people.

Natural disasters of medium size and stronger caused at least 25,000 deaths around the world in 2001, more than double the number the previous year, and economic losses of US \$36 billion (Duncan [11,15]). More recently, humanmade and natural disasters in 2004 claimed more than 21,000 lives worldwide and economic losses of US \$105 billion. According to Mark Pelling of Kings College, London, 2007 is likely to be among the worst years on record for extreme weather disasters (Duncan [13]).

Health impacts of natural disasters include: physical injury, decreases in nutritional status, particularly in children, increases in respiratory diseases resulting from crowding of survivors, impacts on mental health, which in some cases can be long-lasting, increased risk of water-related diseases as a result of disruption of water supply or sewage systems, and release and dissemination of dangerous chemicals from storage sites and water disposal sites into flood waters (Duncan $[11,12,15])$.

It is important to recognize that gender relations significantly affect the daily lives of women and men, before, during, and after a disaster. On balance, men tend to have greater access to key survival and recovery resources (Duncan [15]). Women's social, economic, and political position in many societies makes them more vulnerable to natural disasters, and particularly vulnerable women include: poor or low income women, senior/frail women, women with disabilities, women heading households/single mothers/widows, refugee women and the homeless, indigenous women/minority women, immigrant women/women with language barriers, isolated women/rural women, battered women/women at risk of violence (Duncan [12,13]).

During disasters, women often work to keep the family together. For example, during the 1997 Red River flood, women: diked, spent 'countless hours in the kitchen' preparing meals, serving meals, and cleaning up after meals'; and responded to emotional needs during and after crisis. 'Keeping things normal under abnormal circumstances was a full-time job, and for many, often easier said than done'. In fact, a year after the flood, 'many hours each and every day were still spent on the 1997 flood (Duncan [12,13])'. 
Women are at increased risk of violence in the aftermath of a disaster. Violence may increase during the lengthy recovery period-sometimes, six months to a year after the event.

Police reports on domestic violence in the seven months after Mt. St. Helen's eruption in 1980 increased by 46\%. Santa Cruz's battered women's shelter reported that requests for temporary restraining orders increased $50 \%$ following the 1989 Loma Prieta earthquake. Subsequent to the 1993 Missouri floods, the average state turn-away rate at shelters rose 111\%; programs sheltered $400 \%$ more flood-impacted women and children than anticipated. Moreover, a Montreal urban Police Chief reported that one in four calls he had received during the 1998 Canadian ice storm were from abused women (Duncan [1113]).

\subsubsection{Changing environment}

What does increasing extreme weather events mean for disaster managers, and how do these events impact managers' legal and ethical responsibilities to prepare and respond?

Regarding pandemic influenza, there is the potential for legal liability if planning is not undertaken in a timely manner, as a pandemic could be considered 'reasonably foreseeable'. In the Province of Ontario, Canada, for example, Directors and officers could, in fact, be under a legal duty to prepare, and employees could be eligible for compensation benefits (Duncan [16]).

Could we see similar issues regarding climate change and severe weather events in the future, as failure to address potential natural disasters will expose business, civil society, and government to personal, social, and economic losses (Duncan [13]? For example, the 1998 ice storm forced business to a halt; $19 \%$ or 2.6 million of Canada's workforce were simply unable to travel to work, and 136,000 Quebecois worked in areas where power was not restored for nearly two weeks (Duncan [16]).

What is, therefore, necessary in terms of risk assessment regarding climate change and extreme weather events? Disaster managers should assess risk of exposure to both employees and the public, consider worse-case scenarios, and document the risk assessment process, including the control measures and resources currently in place and those that may be obtained to further reduce risk; the risk assessment should be reviewed regularly.

Disaster managers must establish critical stages, priorities, and roles for extreme weather events, as well as steps to prevent the emergency, appropriate response should it occur, and steps to recover from an emergency. Procedural steps should address the 'five W's' (who is involved? what are they required to do? where, when and how should they carry out each task? why completion of task is so important?), and can be organized into time intervals, such as 0-2 h, 24 h, 4-8 h, 8-24 h (Duncan [16]; Keith [17]).

Disaster managers must also be responsible for overseeing instruction and training of all individuals so that they know their roles. Informed employees who feel safe at work are less likely to be absent during an extreme event. Importantly, contractors, visitors, and volunteers are often left out of training, but should also be included. 
Executing regular emergency drills will help disaster managers and other personnel prepare for an actual emergency, and can be used to assess effectiveness of the plan. Norm Fraser, Vice President of Operations for Hydro Ottawa, reported after the 1998 ice storm that, 'Essentially we ran out of people. People got tired, they went home and you need enough people that are well trained and rehearsed so they're reasonably familiar...the only way to do that is to conduct drills on a regular basis (Duncan [16]).'

During an extreme weather event, communication is vital (Keith [17]). In the first week of the ice storm, telecommunications were paralysed. Marc Lavallee, Assistant to the Deputy Minister of the Ministry of Public Security for Quebec, reported that: 'Without knowing the basic needs of the people affected by the disaster, it was impossible to quickly come to their rescue and, conversely, since the municipalities could not let us know what they expected, we were not able to respond to them. With no means of communication, it was a complete impasse.'

Poor communication is considered to be a major contributing factor to the loss of many first responders during the collapse of the World Trade Center towers. Lack of communication following Hurricane Katrina, which downed 1500 cell phone towers, and left three million customers without service, led to poor situational awareness. For example, a levee breech was reported to the National Weather Service at 9:12 am; in contrast, the Homeland Security Operations Center reported to the Whitehouse that they had not been breeched even at 6:00 pm.

Lack of communication following the hurricane required that people write messages on scraps of paper and drop them in bottles; and meant that evacuation efforts were delayed and duplicated, supplies were delivered to the wrong groups, and sensationalist stories were released by the media (members of the public were largely aware of the horrendous conditions and deaths at the Superdome, but were unaware of the seven births at the same location).

During an extreme weather event, communication and back-up specialists are required to obtain reports and provide briefings, as well as up-date websites, designated lines, list-servs, etc., regarding what is open, what is not, and instructions for employees (Duncan [16]).

\subsection{Diseases associated with water}

There are more than nine million cases of water-borne disease each year in the United States, despite the fact that more than 200 million people in the United States have access to treated water; for example, marine-related illness increased during El Nino events over a 25-year period in the United States. In 1987, warm water associated with an El Nino event caused shellfish poisoning off Prince Edward Island, Canada; 107 people were affected, and 19 required hospitalisation. In 1993, an outbreak of cryptosporidium caused 400,000 cases of the disease in Milwaukee. A positive correlation between rainfall, cryptosporidium oocyst and giardia cyst concentrations in river water, and human disease outbreaks has been noted (Cohen and Miller [4]). 
Increases in ambient temperatures, a prolonged summer season, increased heavy rainfall and/or runoff events may increase waterborne disease in the future (Duncan et al., [8]; and Cohen and Miller [4]).

Therefore, what does the increased threat of waterborne diseases mean for disaster management? Perhaps managers should be involved in identifying vulnerable areas and people, ensuring increased monitoring of surface water and sewage/sanitation systems, identifying meteorological conditions, which may impact water supply, and perhaps even increasing medical capacity during key periods?

\subsection{Air pollution}

The United States Environmental Protection Agency (EPA) reported in 1989 on the magnitude of industrial injection of chemicals into the atmosphere. In 1987, U.S. sources released into the atmosphere 2.7 billion pounds of pollutants, of which 360 million pounds might have been carcinogenic. A total of 1,600 industrial facilities in 46 states emitted carcinogens into the air - 125 of them, more than 400,000 pounds per year. In 1997, approximately 107 million Americans lived in counties that did not meet air-quality standards for at least one regulated pollutant. In 2006, 103 million people nationwide lived in counties with pollution levels above national air quality standards (Duncan [5]). In Canada, more than half of the population lives in areas, in which ground-level ozone may reach unacceptable levels during the summer months (Duncan et al., [8]).

Climate change is likely to increase acidic precipitation, particulates, and smog, with health effects ranging from severe, uncommon events (e.g. death) to mild, common events (e.g. eye, nose and throat irritation) (Duncan et al., [8]; and Cohen and Miller [4]).

What does this increased risk of air pollution mean for disaster management? Should managers be involved in developing air pollution warning systems, and identifying vulnerable people, such as those with cardiac and respiratory problems? Should managers be involved in recommendations to increase hospital capacity?

Numerous studies have demonstrated that hospital admissions for respiratory illnesses are increased during air pollution episodes (e.g. when acid aerosols, ozone, or particulates are elevated). For example, air pollution is thought to be responsible for 1700 premature deaths and 6,000 hospital admissions in the City of Toronto, Canada, each year (Health Canada [18]).

\section{Summary}

In order to stabilize climate change altogether, emissions of carbon dioxide $\left(\mathrm{CO}_{2}\right)$ would have to be reduced by approximately $70 \%$. The main challenge is the length of time $\mathrm{CO}_{2}$ remains in the atmosphere, as it can take 100 years for it to disperse. Therefore, even if humans stopped $\mathrm{CO}_{2}$ emissions immediately, the effects of industrialization would still influence weather for years to come (Ahrens [19]; and Harvey [20]). 
Weather-related disasters and losses are, however, increasing today; the year 2005 was the hottest year in a century, and seven of the ten most expensive hurricanes in American history occurred between August 2004 and October 2005.

Twenty years ago, average yearly-insured losses caused by severe weather were US \$3.7 billion, and economic losses were $\$ 29.4$ billion. The year 2005 was the costliest on record, with $\$ 78$ billion in insured losses, and $\$ 230$ billion in economic losses (McGillivray and Sandinak [21]).

Weather hazards projected for the $21^{\text {st }}$ century are likely to have a profound effect on communities and people around the world: for example, higher maximum temperatures leading to an increase in illness and death, as well as increased cooling demand, and reduced energy supply reliability (Cohen and Miller [4]).

Glen McGillivray, Managing Director for Canada's Institute for Catastrophic Loss Reduction reports that, 'Although we can do little to affect the incidence of weather hazards in the near term, we can reduce our vulnerabilities to these hazards and, hence, limit the impact (McGillivray and Sandinak [21]).'

For communities at risk, a first step is having disaster managers recognize that climate change presents a significant challenge; a second step is building capacity for natural hazard reduction. Disaster managers must work to prevent illness, injury, and death, and to establish resilient communities.

\section{References}

[1] IPCC. 2007. Climate change 2007: the physical basis. Summary for policymakers. http://www.ipcc.ch. 26/02/07.

[2] Houghton, J., Filho, L., Callender, B. et al. 1995. Climate Change 1995: The Science of Climate Change. Contribution of Working Group 1 to the Second Assessment Report of the Intergovernmental Panel on Climate Change (IPCC). Cambridge University Press.

[3] Houghton, J., Ding, Y., Griggs, D. et al. (eds). 2001. Climate Change 2001: The Scientific Basis. Contribution of Working Group 1 to the Third Assessment Report of the Intergovernmental Panel on Climate Change (IPCC). Cambridge University Press.

[4] Cohen, S. and Miller, K. 2001. North America. In: McCarthy, J., Canziani, O., Leary, N. et al. Climate Change 2001: Impacts, Adaptation, and Vulnerability. Contribution of Working Group 11 to the Third Assessment Report of the Intergovernmental Panel on Climate Change (IPCC). Cambridge University Press.

[5] Duncan, K. 2008. Environment and Health: Protecting Our Common Future. WIT Press.

[6] McCarthy, J., Canziani, O., Leary, N. et al. 2001. Climate Change 2001: Impacts, Adaptation, and Vulnerability. Contribution of Working Group 11 to the Third Assessment Report of the Intergovernmental Panel on Climate Change (IPCC). Cambridge University Press. 
[7] World Summit on Sustainable Development (WSSD). 2002. World Summit on Sustainable Development 2002. Facts about protecting natural environments.

http://www.johannesburgsummit.org/htm/media_info/pressreleases_factshe et/wssd7_environment.pdf. 03/07/03.

[8] Duncan, K., Guidotti, T., Cheng, W. et al. 1998. Health Sector. In The Canada Country Study: Climate Impacts and Adaptation. Koshida, G. and Avis, W. Environment Canada. pp. 501-590.

[9] World Health Organization (WHO). 2007. Human health is especially affected by climate change. http://www.euro.who.int/globalchange/ Assessment/20070404 2. 04/07/08.

[10] MMWR. 1984. Heat-associated mortality—New York City. MMWR July 27, 1984: 33 (29): 430-2.

[11] Duncan, K. 2006. Climate change, health, and women. Climate Change and Health Impacts Atlantic Conference 2006. St. John's, Newfoundland and Labrador, March, 2006.

[12] Duncan, K. 2007a. Global climate change and women's health. Women and Environments International Magazine No. 74/75: 10-11.

[13] Duncan, K. 2007b. Climate change and emergency preparedness: reducing risks, saving lives. 20th Annual Emergency Preparedness Conference, Vancouver, November, 2007. http://www.jibc.ca/epconference/2007_ conference/program.htm. 04/07/08.

[14] Kovats, S. and Kristie, E. 2006. Heat-waves and public health in Europe. The European Journal of Public Health 16(6):592-599.

[15] Duncan, K. 2004. Initial links: climate change, water, women, and health. Water and Climate Change: Knowledge for Better Adaptation. Canadian Water Resources Association Conference Proceedings.

[16] Duncan, K. 2007c. Engaging and strengthening employee disaster preparedness. Business Continuity and Pandemic Preparedness: Planning, Partnership, and Participation. http://www.conferenceboard.ca/documents. asp?rnext=2049. 07/01/08.

[17] Keith, N. 2007. Canadian Emergency Management and Response Manual: A Guide to the Law and Practice. Thomson Carswell.

[18] Health Canada. 2007. People, Place and Health. Health Policy Research Bulletin. November 2007, Issue 14.

[19] Ahrens, C. 2000. Meteorology Today: An Introduction to Weather, Climate, and the Environment. Thomson Learning.

[20] Harvey, D. 2000. Global Warming: The Hard Science. Pearson Education Limited.

[21] McGillivray, G. and Sandinak, D. 2007. Climate change and local government: the changing risk environment. Disaster Management Canada 1 (2): 23-30. 